Tempo Social; Rev. Sociol. USP, S. Paulo, 12(1): 47-68, maio de 2000.

\title{
Da mi-carême ao carnabeach história da(s) micareta(s)
}

\author{
BENOIT GAUDIN
}

RESUMO: Este artigo tem como propósito apresentar a história da micareta no Brasil, desde seu surgimento enquanto mi-carême até seus últimos desdobramentos atuais. A pesquisa se deu em parte sintetizando a escassa literatura relativa ao tema, mas a maioria das informações contidas neste artigo provêm de uma extensiva pesquisa de cunho histórico, em arquivos principalmente jornalísticos, de publicações cearenses, soteropolitanas e nacionais. A micareta aparece como uma festa bastante antiga (existindo desde 1908), com uma rica história intimamente ligada ao carnaval de Salvador e à evolução dos trios elétricos e das bandas de trios baianas. Correspondendo às sucessivas fases de expansão da festa pelo país, cinco etapas foram caracterizadas nessa evolução, cujo traço marcante foi o gradativo processo de comercialização sofrido na contemporaneidade.

\section{A mi-carême de Salvador}

uando se pesquisa sobre as origens da micareta na literatura histórica e folclórica nacional, descobre-se duas festas: uma alcunhada de serração da velha e outra que leva um nome francês: mi-carême. Documentada principalmente por Julio Caro Baroja em seu El Carnaval, analisis historico-cultural (Baroja, 1979), a serração da velha é uma tradicional e antiga festa ibérica cuja origem no Brasil, segundo João Carlos Sebe, "está presa à influência francesa no Brasil, através de Portugal, no século XVIII" (Sebe,1986, p. 85). Na península ibérica, a Quaresma era simbolizada por uma

UNITERIMOS:

carnaval, comercialização da cultura, indústria cultural, história cultural, mi-carême, micareta, trio elétrico.
Doutorando em Sociologia na Université Aix-Marseille I 
velha senhora feia, magra e comprida como um tempo de abstinência. A analogia com o período magro se estendia até a anatomia da velha, representada por um boneco de sete pés, da mesma forma que a Quaresma conta sete semanas. A cada semana, um pé era arrancado do boneco e, na metade das sete semanas, o próprio boneco era serrado pela metade (cf. Baroja, 1979, p. 132-141). Em Portugal, a leitura pública de um "testamento" burlesco acompanhava às vezes a cerimônia de serração (cf. Diego, 1960, p. 303-304 apud Baroja, 1979, p. 141). No Brasil, João Carlos Sebe registra a existência da festa, cuja inspiração "está ligada à dramatização de uma velha (símbolo de morte, doenças e desgraças) que seria serrada entre gritos e uivos do público em geral"' (Sebe, 1986, p. 85).

Já a mi-carême (essa é a grafia correta em português, segundo o dicionário Aurélio) é uma festa de origem francesa cujo surgimento no Brasil aconteceu muito mais tarde, no início do século XX. Naquela época, a moda pela França era tão vivaz que o próprio período leva nome francês: Belle Époque. A vida cultural da capital da República era altamente influenciada e inspirada por Paris e, na ocasião do carnaval, o lance-parfum era especialmente importado da França. Neste contexto, não demorou muito para aparecerem iniciativas visando a implantar no Rio de Janeiro a mi-carême.

Conta o historiador francês Alain Faure, no seu livro Paris, carême prenant, que em Paris a festa acontecia entre várias categorias da população da capital francesa: os açougueiros, as lavadeiras e os estudantes (cf. Faure, 1978, p. 133-142), cada grupo desfilando num determinado percurso e, em alguns anos, se juntando nas principais artérias de Paris num grande desfile popular. As lavadeiras tinham a particularidade de eleger sua rainha antes de desfilar num carro alegórico de fortuna onde o grotesco reinava solto. Já os estudantes tendiam mais para a ironia crítica e a sátira.

Eneida de Moraes, pioneira na historiografia do carnaval carioca, relata que esta festa já era conhecida no Rio de Janeiro desde 1908: "em 1908, a Fon-Fon, revista ilustrada mundana, elegante, propunha que se realizassem festas de mi-carême dedicadas aos operários. Cada fábrica elegeria sua rainha e damas de honra que desfilariam pela Avenida no sábado de Alelúia" (Moraes, 1987, p. 164). Observa-se que, apesar do nome mi-carême ("meia-quaresma"), a festa mudou de data ao atravessar o Atlântico, numa exemplar ilustração da plasticidade das datas festivas brasileiras evidenciada por Bastide como típica de um folclore de importação (cf. Bastide, 1970, p. 158-163).

Contudo, nem a serração da velha nem a mi-carême confundiam-se então com o carnaval. Eram festas distintas, festejos diversos, costumes diferentes. Essa situação perdurou até 1914, data em que, pela primeira vez, a micarême foi comemorada como se fosse um verdadeiro carnaval, ou melhor, um "carnaval fora de época". Essa estréia aconteceu em Salvador e foi uma iniciativa do clube carnavalesco soteropolitano Fantoches da Euterpe, que obteve a adesão dos dois outros grandes clubes da época, o Cruz Vermelha e o Inocentes em Progresso (cf. Duarte, 1997, p. 4). A proposta explícita desses clubes era de organizar um "segundo carnaval do ano" e como eles já conheciam a mi-carême, que acontecia no final da Quaresma, efetuaram a fusão entre essa festa mascara- 
GAUDIN, Benoit. Da mi-carême ao carnabeach - história da(s) micareta(s). Tempo Social; Rev. Sociol. USP, S. Paulo, 12(1): 4768 , maio de 2000.

da e o carnaval. Vale lembrar que estávamos então na chamada Belle époque e que nada tinha de incoerente a idéia de repetir o carnaval, uma festa nitidamente européia na época, por ocasião de outra festa de nome francês.

Arespeito dessa estréia, a folclorista baiana Hildegardes Vianna conta ainda que a festa nasceu como "promoção comercial para salvar do fracasso total o carnaval, que vinha perdendo terreno na aceitação popular" (Vianna, 1970, p. 24). Fracasso total do carnaval? Promoção comercial, já em 1914? Precisamos voltar um pouquinho ao contexto da época para entender isso melhor.

O carnaval dessa época era o chamado "Grande Carnaval": tratavase de uma festa altamente elitista que se inspirava nos carnavais de Veneza e de Nice, este último sendo então considerado o maior do mundo. As elites baianas, pelo menos os mais endinheirados dos seus representantes, iam desfrutar as delícias dos festejos momescos na França ou na Itália e voltavam cheias de idéias para animar suas cidades (cf. Nobre, 1978, p. 536). Nas primeiras décadas da festa (1840-1880) porém, os folguedos se limitavam a bailes mascarados nos clubes elegantes da cidade e a um corso de carruagens ou automóveis pelas ruas do centro. Afora alguns mascarados avulsos chamados de "caretas", o povo em nada participava dos festejos, a não ser como mero espectador.

Esse carnaval era uma novidade em Salvador como nas outras cidades do Brasil, pois na capital da Bahia, até os anos 1880, era o velho, violento e primitivo entrudo que reinava solto durante os Dias Gordos: essa brincadeira muito popular consistia basicamente em atirarem uns nos outros água, farinha e outras coisas sujas... ${ }^{1}$ Com os anos 1880, o "civilizado" carnaval começou a sobrepujar o "bárbaro" entrudo nos festejos da cidade, graças à intensa campanha moralizadora liderada pela imprensa e acompanhada de proibições e repressão policiais (cf. Vianna, 1965, p. 285; Fry, 1988, p. 236-245)2.

Na luta contra o entrudo, os clubes contavam não somente com o apoio da imprensa, da polícia e até da Igreja, como também do comércio que enxergava nesse carnaval uma oportunidade de lucro bem maior, quando comparado ao entrudo: para brincar o carnaval, precisava-se de confeitos, de seringas, de máscaras, de fantasias (alugadas ou compradas), apetrechos todos muito custosos, especialmente quando importados da Europa. Para as grandes casas de comércio, muitas vezes intimamente ligadas aos clubes sociais na organização dos festejos (cf. Nobre, 1978, p. 537 ; Fry, 1988, p. 248), o carnaval era portanto um ótimo negócio (cf. Vianna, 1965, p. 286) ${ }^{3}$.

Na década de 1880, aconteceu a junção do carnaval de rua (o préstito) com o carnaval de salão (os fantasiados dos bailes) e dessa união nasceram as associações carnavalescas. Organizadas pelos mesmos clubes chiques que promoviam os bailes, elas desfilavam ao som de árias de ópera, polcas, marchas e outras músicas de inspiração européia, encenando temáticas da mitologia greco-romana ou das cortes francesa e italiana (cf. Fry, 1988, p. 249).

Tudo transcorria maravilhosamente para a mais européia das festas baianas até que um elemento inesperado da população resolveu ingressar nessa festa de elite: em 1888, com a Lei Áurea, os escravos se tornavam formalmente cidadãos brasileiros e, a partir de então, nenhuma lei impedia suas ma-
${ }^{1}$ Para maiores informações sobre o entrudo e as etapas históricas do carnaval no Brasil, cf. Queiroz (1992).

2 Sobre semelhante postura dos poderes constituídos, porém no contexto paulista, cf. Von Simson (1985).

3 Outra ilustração do interesse do setor comercial no carnaval (dentro do contexto paulista) pode ser encontrada em Von Simson (1984). 
nifestações culturais, sejam elas batuques, candomblés ou qualquer outra expressão de uma tradição de origem africana. Até a abolição da escravatura, essas práticas eram proibidas ou reprimidas e sobreviveram unicamente graças ao sincretismo que se operou entre elas e as cerimônias e festas de origem européia, por ocasião das quais suas manifestações (danças, ritmos e ritos) eram apenas toleradas (cf. Verger, 1980, p. 2-8).

A partir de 1888, ganhando pleno direito ao espaço público, as manifestações da cultura africana puderam exprimir-se e exibir-se mais livremente, especialmente durante as festas carnavalescas: perpetuando a tradiçãode sincretismo na festa, os ex-escravos adotaram as formas organizacionais dos desfiles dos clubes sociais, adaptando-os às suas características culturais. Nasciam assim os "préstitos africanos", verdadeiros desfiles organizados nos moldes dos préstitos burgueses com a diferença de exaltar a cultura africana ao som dos batuques em vez de prestigiar a cultura européia (cf. Fry, 1988, p. 251-252). Data desta época também o surgimento no carnaval dos afoxés (então chamados de candomblés) e dos cucumbis, pequenos grupos de mascarados dançando ao som de sambas e de batuques (cf. Verger, 1980, p. 10; Vieira Filho, 1995, p. 100). Os "préstitos africanos" foram tão populares e tão luxuosos que, a partir de 1892 e até 1905 , "abafaram" os préstitos dos clubes da alta sociedade que, nesse período, se apresentaram apenas de maneira intermitente (cf. Fry, 1988, p. 250).

Frente a essa evolução, a mesma aliança que tinha combatido o entrudo poucos anos antes (imprensa, igreja, poder público) entrou em guerra contra essa forma "africanizada" de brincar carnaval e, a partir de 1903, a Câmara Municipal e as autoridades policiais baixaram uma série de medidas visando limitar e reprimir todas as manifestações de uma estética não europeizada. Assim, em 1905, o chefe da polícia resolveu impedir a saída do carnaval dos clubes ou grupos de mascarados afro-mestiços, proibindo expressamente a "exibição de costumes africanos com batuques" (Jornal de Notícias, 24/02/1905, apud Fry, 1988, p. 253). A partir de então e até 1914, a repressão policial contra as formas culturais e religiosas de origem africana foi incessante e suficientemente bem aplicada para efetivar a saída do elemento africano dos folguedos momescos da cidade (cf. Fry, 1988, p. 256). Em conseqüência, o carnaval de Salvador passou a viver uma fase bastante desanimada.

Foi nesse contexto de recesso carnavalesco e de repressão policial que os clubes elegantes da burguesia, junto aos comerciantes da cidade, resolveram reaquecer as vendas de produtos festivos e recuperar a iniciativa da festa, promovendo um "segundo carnaval do ano" disfarçado de mi-carême.

A festa foi logo um sucesso, apesar de escandalizar a opinião pública e de provocar uma forte perseguição das autoridades católicas por acontecer em pleno domingo de Páscoa. Mesmo assim, a mi-carême foi adotada por quantos gostavam da folia e teve longos anos de glória na capital da Bahia. As críticas e condenações da Igreja, porém, fizeram com que a festa fosse transferida do domingo de Páscoa para outro domingo, fora do período de abstinência religioso. Segundo Vianna, com essa mudança de data, a mi-carême "perdeu o sabor, ameaçando morrer" (Vianna, 1970, p. 24). 
Esse processo de recesso da mi-carême da capital se deu enquanto o carnaval retomava forças: durante a década de 1930 e até a Segunda Guerra Mundial, Salvador conheceu alguns dos seus melhores carnavais (cf. Vianna, 1970, p. 24): particularmente ricos e suntuosos, os desfiles de carros alegóricos serviam às elites da cidade como palco para suas rivalidades econômico-políticas, cada grupo querendo superar o outro em riqueza, ostentação e magnificência (cf. Queiroz, 1992, p. 53). O fausto e a animação deste "carnaval-espetáculo" tornavam supérflua a existência de um outro carnaval, fora de época, e a micarême foi paulatinamente perdendo espaço. $\mathrm{O}$ ano de 1942 guardaria o último registro desta festa na capital baiana (cf. Duarte, 1997, p. 4).

Passando de domingo em domingo calendário adentro, a festa já não tinha mais por que ser chamada de mi-carême, especialmente numa época em que a moda de afrancesamento da sociedade perdia fôlego. Em 1935, a imprensa soteropolitana patrocinou um plebiscito para definir o novo nome dessa festa e a opção de micareta, provável corruptela de mi-carême com careta (mascarado) foi escolhida (cf. Vianna, 1970, p. 24).

\section{A micareta vai para o interior}

Em Salvador, os carnavais dos anos 30 foram tão magníficos e animados que atraíam foliões de outras cidade do estado; quem morava no interior e tinha condições de passar os Dias Gordos na capital não dispensava a viagem para Salvador. Essas "migrações festivas" eram facilitadas pela construção de rodovias ligando a capital às cidades do Recôncavo, como a rodovia Salvador-Feira de Santana, em 1931 (cf. Alencar, 1968, p. 21). Com esse "êxodo momesco", muitas cidades interioranas viram seus carnavais enfraquecerem, a exemplo de Feira de Santana, cujo carnaval já vinha sofrendo devido à proximidade da capital do estado; a partir da abertura da rodovia Feira-Salvador, as elites da cidade, ao se ausentarem, deixavam o povo feirense com poucas animações festivas (cf. Poppino, 1968, p. 288-289). Carnaval verdadeiro aliás, a cidade só teve entre 1929 e 19364, mesmo assim sem o esplendor dos carnavais da capital nem das micaretas que viriam a acontecer depois de 1937 (Panorama, 1987, p. 12).

Para compensar o enfraquecimento do seu carnaval, Feira de Santana adotou a micareta que já era conhecida... de outros carnavais. Interessante é notar que o fenômeno de adoção da micareta por cidades do interior baiano começou desde bastante cedo, já nos anos 1920, e aconteceu em outras cidades além de Feira de Santana: a título de exemplo, Irará, pequena cidade do Recôncavo, já tinha seu "segundo carnaval do ano" em 1927 (Folha do Norte, 1928).

Foi em Feira de Santana, porém, que a micareta conheceu seu maior êxito fora da capital: em 1937, uma chuva diluviana impediu que o carnaval fosse comemorado normalmente e os foliões feirenses, inconformados e frustrados, decidiram postergar os festejos momescos, realizando-os algumas semanas depois da data convencional. O sucesso do primeiro "carnaval fora de época" feirense que surgiu dessa decisão foi tal, que a festa se repetiu nos anos seguintes e tornou-se a mais animada do ano, eclipsando o próprio car-
${ }^{4}$ Poppino (1968, p. 288) conta que, no século XIX, Feira já tinha carnaval, e continuou tendo, mesmo que de forma intermitente, durante as primeiras décadas do século XX. O autor faz menção a um carnaval em 1925, mas em 1928, a Folha do Norte não dá nenhum registro de festa carnavalesca na cidade. 
naval que, a partir de então, deixou totalmente de ser celebrado.

Com a micareta, o que era prejudicial a Feira tornou-se benéfico: a proximidade da capital fez com que os foliões soteropolitanos viessem a Feira reforçar a animação dos festejos, tornando essa festa uma das mais badaladas do calendário festivo do estado. Assim, logo em 1937 o Clube Carnavalesco Cruz Vermelha, campeão do carnaval de Salvador naquele ano, trouxe dois carros alegóricos e muita animação da capital. Da mesma forma, em outros anos, o famoso clube dos Fantoches da Euterpe também participou da micareta feirense (Panorama, 1987, p. 13).

Em Feira, o nome da festa também criou polêmica: os opositores aos "francesismos" criticavam duramente a terminologia mi-carême que a festa conservou nos primeiros anos; o principal organizador da festa defendia o nome de Páscoa Carnavalesca (cf. Alencar, 1968, p. 28) enquanto outros sugeriam Refolia. Coube a alguns intelectuais da cidade definir de vez qual seria o nome desta festividade e mi-carême acabou ganhando das outras opções (Panorama, 1987, p. 12). Durante alguns anos, a festa continuou com esse nome, antes de finalmente ser rebatizada de micareta, provavelmente por causa da preferência popular ou do exemplo de Salvador.

De 1937 até 1951, data da primeira participação de um trio elétrico, a micareta feirense foi festejada nos moldes tradicionais do carnaval da época: bailes nos clubes sociais da cidade, préstitos de carros alegóricos, mascarados avulsos nas ruas, concursos de fantasias, além, claro, da tradicional eleição da Rainha e de seu desfile pelas ruas da cidade. Nas ruas também desfilavam elegantes cordões como As Melindrosas (até 1941), Flor de Carnaval e Filhos do Sol (Feira Hoje, 1987). Acompanhando a evolução do carnaval nacional, a festa passou também a contar com formas de participação mais diversificadas como cordões puxados por charangas, blocos variados e batucadas (essas últimas permanecendo até os anos 50, antes de se transformarem em escolas de samba e depois em blocos de índios) ${ }^{5}$. Foi o trio elétrico que veio revolucionar tudo isso.

\section{A revolução do trio elétrico}

Em 1949, dois eletrotécnicos e músicos de Salvador, Osmar Macedoe Antônio Adolfo do Nascimento (o Dodô), inventaram o que mais tarde seria o trio elétrico: em 1949, ainda não se falava de trio mas sim de dupla elétrica, pois os dois se apresentavam sós, tocando num carro aberto (um velho Ford Fobica de 1929), com suas guitarras baianas (também invenção deles) ligadas na bateria do carro. Não cantavam, por não terem ainda integrado o microfone à sua invenção, e

Para maiores informações sobre a evolução das formas de participação popular no carnaval da Bahia após 1950 (cf. Moura, 1987; Morales, 1990, 1991; Gomes, 1989). tocavam exclusivamente frevo, inspirados pela Banda Mista Vassourinhas de Recife que acabara de se apresentar no carnaval da Bahia (cf. Góes, 1982, p. 17-18). Sua primeira aparição pública criou uma imensa surpresa no carnaval de Salvador de 1950 e seu sucesso junto à população foi enorme, os espectadores do corso passando a acompanhar o carro, dançando pelas ruas da cidade.

Bastante orgulhosos de suas invenções (a "guitarra baiana" e o "veí- 
GAUDIN, Benoit. Da mi-carême ao carnabeach - história da(s) micareta(s). Tempo Social; Rev. Sociol. USP, S. Paulo, 12(1): 4768 , maio de 2000.

culo sonoro"), Dodô e Osmar queriam divulgar suas engenhocas mundo afora: em 1951, depois de repetir o sucesso do ano anterior, resolveram apresentar-se na micareta de Feira de Santana, puxando os famosos Fantoches que tinham viajado para Feira com eles (cf. Duarte, 1997, p. 4).

Em 1952, o trio elétrico já tinha sua estrutura básica: um terceiro músico se juntara à dupla original, dando o nome atual ao conjunto eletrizado, o velho Ford fora substituído por um caminhão e o modelo já fora copiado por três outras entidades: os trios ${ }^{6}$ Cinco Irmãos, Ipiranga e Conjunto Atlas. Esses trios conheceram um sucesso estrondoso nos carnavais seguintes e sua fama já começava a ultrapassar os limites da capital. Conta o próprio Osmar Macedo: "Nós fomos tocar na famosa micareta de Feira de Santana em 1952, aí recebemos convite do Prefeito de Alagoinhas para fazermos a micareta de lá no ano seguinte. Eu disse, então, que já havíamos nos comprometido com a Prefeitura de Feira de Santana de voltarmos a nos apresentar em 1953. Ele resolveu, assim, mudar a data, colocando a micareta de Alagoinhas uma semana depois da de Feira. Em 1953, conseqüentemente, fizemos Feira, uma semana depois Alagoinhas, e lá, outro prefeito veio nos sondar da possibilidade de fazermos também outra micareta, e assim foram aparecendo micaretas por todo o interior baiano" (Góes, 1982, p. 57-58).

Em relação com as micaretas, o trio elétrico introduziu portanto pelo menos duas mudanças profundas: modificou suas datas, que passaram a se estender da Páscoa até o São João, e multiplicou o número de micaretas do interior da Bahia: com a aparição do trio elétrico, a mi-carême/micareta, até então restrita a algumas cidades, se alastrava além do Recôncavo.

$\mathrm{Na}$ base de entrevistas pessoais com os próprios fundadores do trio elétrico, Góes (1982, p. 58) informa que “entre 1952 e 1957, [eles] se apresentaram nas ruas de Salvador e nas micaretas interioranas, sob o patrocínio de Fratelli Vita". Na década seguinte, quando Dodô e Osmar venderam seu trio ao dono dos Tapajós, esse conta que foi "fazer as micaretas de Feira de Santana, Pojuca, Catu e Alagoinhas, em 1961. [...] Fazia quatro, cinco, seis micaretas por ano sob o patrocínio da Coca-Cola e das prefeituras locais. [...] Fizemos os carnavais de 65, 66 e 67 [em Salvador] e, como tricampeões, tocamos em dezenas de micaretas..." (Góes, 1982,p. 61-63). As micaretas se espalhavam soltas pela Bahia, limitadas somente pelos recursos dos municípios e, provavelmente, pelas condições precárias das estradas: os trios começavam a se transformar em enormes caminhões e precisavam de estradas relativamente boas para se deslocarem.

Foi portanto o trio elétrico que esteve na origem de muitas micaretas interioranas na Bahia das décadas de 50 e 60 . A partir de então, a história da micareta e a do trio elétrico se entrosaram estreitamente, pois foi com o dinheiro arrecadado durante as diversas micaretas que os trios conseguiram se modernizar. As micaretas davam aos trios a oportunidade de sair várias vezes no mesmo ano, em vez de ficarem parados o ano inteiro à espera do carnaval ${ }^{7}$ (cf. Góes, 1982, p. 58-63). Sem essa possibilidade de rentabilizar os trios, os donos dos mesmos dificilmente teriam conseguido adquirir equipamentos eletro-acústicos cada vez mais sofisticados, nem pagar o cachê de músicos
${ }^{6}$ Rapidamente a expressão "trio elétrico" passou a designar não só o conjunto musical mas também o caminhão no qual desfilavam.

${ }^{7}$ Outra utilização rentável do trio elétrico, descoberta desde cedo, foram as campanhas eleitorais e os lançamentos comerciais (cf. Góes, 1982, p. 61-63). 
que se tornaram conhecidos. Essa parceria trio-micareta animou dezenas de carnavais e de micaretas durante longos anos antes de sofrer, nos anos 70, uma crise de financiamento, justamente por causa da crescente modernização e profissionalização dos trios.

Até o final dos anos 70, atrás do trio elétrico pulava quem bem queria, tanto em Salvador como nas micaretas do interior do estado. A festa era inteiramente aberta e pública, não havia cordões de isolamento ao redor dos trios e quem pagava os artistas e os custos ligados ao(s) trio(s) eram os patrocinadores (geralmente empresas de bebidas) e as prefeituras que organizavam as micaretas, nos anos em que o orçamento municipal permitia. Várias cidades do Recôncavo e de outras regiões do interior baiano organizavam suas micaretas assim, de maneira intermitente, dependendo dos recursos municipais do ano.

\section{A crise da parceria trio-micareta}

Enquanto as micaretas eram animadas por poucos trios, sendo estes simples caminhões equipados de alto-falantes tendo como músicos os inventores (no caso de Dodô ou Osmar) ou meros desconhecidos (no caso das novas bandas que surgiam na Bahia), a parceria trio-micareta continuou frutífera, multiplicando o número de micaretas e modernizando os trios. Mas quando, nos meados da década de 70, o trio começou a contar com o que existia de mais moderno no mercado e a apresentar artistas famosos, ficou muito mais difícil para os municípios interioranos arcarem com as despesas da festa e manterem suas micaretas vivas. Esse problema, aliás, aconteceu também com a Prefeitura de Salvador e a organização do seu carnaval.

E o trio elétrico evoluiu bastante: modernizou-se muito, ganhando carroceria especial, dimensão e potência sonora multiplicadas, microfones para os vocalistas, seção inteira de percussionistas, iluminação própria, e até canhões de confetes, elevadores internos e palcos giratórios (cf. Góes, 1982, p. 59, 62, 81 e 86). Da mesma forma, artistas e músicos de fama nacional (como Caetano Veloso ou os Novos Baianos) começaram a cantar nos trios e os músicos locais, que haviam sido descobertos no carnaval de Salvador, começaram a se tornar célebres e seus cachês, caros. Os custos ficaram então altos demais para as prefeituras interioranas, ameaçando o futuro das suas micaretas.

Com o encarecimento dos trios, os patrocinadores deixaram de considerar o trio elétrico como um suporte publicitário rentável, alegando que a fama dos artistas prejudicava a divulgação do nome da empresa (cf. Góes, 1982, p. 81). Da mesma forma, a Prefeitura Municipal de Salvador não podia mais (ou não queria) subvencionar todos os trios, cujo número aumentava com o sucesso que a festa começou a angariar no final dos anos 60. Os meados da década de 70 são portanto anos de crise para os trios, para o carnaval de Salvador e para as micaretas. Em Salvador, por exemplo, os trios não acompanhavam toda a programação prevista pela prefeitura, deixando de comparecer a certos eventos do carnaval (reclamando assim contra as baixas subvenções que recebiam) e apresentaram músicos de qualidade duvidosa (cf. A Tarde, 1978). 


\section{Os blocos carnavalescos integram o trio elétrico}

Essa crise de financiamento da festa somente foi resolvida com a privatização do espaço festivo, isto é, com a comercialização do direito de acompanhar o trio életrico de perto. A partir desse momento, quem paga a festa é o folião, ficando num segundo plano os patrocinadores e as prefeituras. Essa mudança, tão criticada, tão lamentada, do modelo festivo "trieletrizado" aconteceu pela primeira vez no carnaval de 1977 em Salvador. Naquele ano, três "blocos de elite" (Os Internacionais, o Jacu e o Traz os Montes), reunindo foliões das classes média e média alta, tomaram uma mesma iniciativa: contratar um trio elétrico e inseri-lo dentro do seu respectivo cordão (cf. A Tarde, 1977a; 1977b). Assim nasceram os primeiros "blocos de trio", operando a fusão entre o tradicional cordão carnavalesco e o trio elétrico. Os "associados" dos blocos viram sua cotização aumentar, mas em compensação ganharam acesso garantido e protegido ao espaço que cerca o trio elétrico, numa época em que a segurança do folião "rico" estava sendo ameaçada pela agressividade dos blocos mais populares, sobretudo os blocos de índios ${ }^{8}$.

O processo de comercialização do espaço físico da festa pouco demorou em Salvador: em 1982, quase todos os trios que saíam no carnaval da cidade eram contratados pelos blocos, a não ser o histórico trio de Dodô e Osmar e o dos Novos Baianos (cf. Veja, 1982, p. 41). Mais tarde, percebendo os perigos de uma elitização excessiva do carnaval, a Prefeitura Municipal de Salvador voltou a contratar trios que passaram então a ser chamados de "trios independentes" (por não serem ligados a nenhum bloco).

No interior da Bahia, o novo modelo organizacional da festa (o financiamento da festa pelos blocos de trio) se propagou durante a década de 80, possibilitando o fortalecimento ou o nascimento de dezenas de micaretas num raio que agora ultrapassava muito o Recôncavo, atingindo cidades distantes como Jequié, Itabuna, Ilhéus ou Vitória da Conquista (em 1989), no extremo sul do estado (cf. Duarte, 1997; A Tarde, 1997).

Os dois tipos de financiamento das micaretas (privado e municipal) continuaram, e continuam ainda, a coexistir na Bahia, sendo o financiamento pelos blocos mais comum nas cidades de porte regional (como Vitória da Conquista ou Ilhéus) e o financiamento municipal mais característico de cidades menores, como Saebra, Ipirá, Irecê e dezenas de outros municípios que, muitas vezes, deixaram de festejar carnaval, optando pela micareta. Via de regra, os blocos privados conseguem contratar os melhores artistas e trios da capital, enquanto as prefeituras mais humildes têm de se contentar com trios e bandas locais (cf. Panorama, 1985a, 1988a, 1988b; A Tarde, 1997).

Em Feira de Santana, os blocos começaram a se estruturar em blocos de trio a partir de 1982, a exemplo de Os Nacionais que perdeu seu patrocinador principal naquele ano (pelo fato da empresa julgar que o seu investimento não dava retorno). Foram então os maiores blocos da cidade, como Os Nacionais, Raízes, Uca e Mendonça, que passaram a contratar os mais famosos trios de Salvador com o dinheiro que cobravam dos seus "associados"

${ }^{8}$ Sobre os blocos de índios e o clima do carnaval de rua daqueles anos, cf. Godi (1991, p. 51-71). 
GAUDIN, Benoit. Da mi-carême ao carnabeach - história da(s) micareta(s). Tempo Social; Rev. Sociol. USP, S. Paulo, 12(1): 4768 , maio de 2000.

através da venda de carnês. A prefeitura continuava a contratar trios, mais baratos, para o resto da população (cf. Panorama, 1985b, 1985c).

Independentemente do fato de ser integrado a um bloco ou não, o trio elétrico sempre possuiu, em si, um poder atrativo muito forte. Maria Inês Sampaio já observou e analisou esse poder de atração sobre os foliões, chegando a comparar o trio a um deus, pela força de dominação e de fascínio que exerce (cf. Sampaio, 1983, p. 100). Da mesma forma, já ficou comprovado que uma mesma banda que se apresenta num palco fixo não tem tanto sucesso do que quando toca em cima de um trio: o próprio movimento do trio gera animação e dança. Além disso, o fato do trio desfilar permite a muita gente ter a oportunidade de se encontrar, em um determinado momento, logo ao lado do mágico caminhão: basta se instalar no trajeto do desfile e esperar ele chegar. A esse poder de atração e de animação do trio veio se juntar a força da organização comercial dos blocos de trio que resolveu definitivamente seu problema de financiamento, abrindo assim uma nova era para o carnaval e as micaretas.

\section{A música do sucesso}

Em relação à vida cultural da capital baiana, interessante é notar que o surgimento dos blocos de trio em Salvador bem como nas micaretas, além de viabilizar a modernização dos trios, permitiu também lançar, financiar e profissionalizar muitos artistas baianos, a tal ponto que Salvador se tornou, nos anos 80 e 90, um verdadeiro celeiro de criação musical a nível nacional e internacional (cf. Veja, 1982, p. 41-42).

Do ponto de vista musical, durante décadas as bandas de trio só tocavam frevo elétrico (ou frevo baiano), um estilo musical inventado por Dodô e Osmar ao interpretar com seus instrumentos elétricos as músicas do frevo pernambucano, tradicionalmente tocadas com instrumentos de sopro. Durante anos, também, os trios se apresentaram sem vocalistas. A partir do final dos anos 60, as coisas começaram a mudar: em 1969, Caetano Veloso com Atrás do trio elétrico divulgou a nível nacional o estilo musical dos trios bem como a maneira baiana de brincar carnaval, isto é, de andar acompanhando um trio elétrico em vez de ficar assistindo a um desfile, de "pular" em vez de dançar, de sair de mortalha ${ }^{9}$ em vez de vestir uma fantasia própria, etc. $\mathrm{Na}$ mesma época, o movimento tropicalista operava experiências e fusões musicais que repercutiram na música dos trios: foi nesses anos que músicos como Armandinho e Moraes Moreira integraram o rock ao frevo, em um novo ritmo que batizaram de frevoque (cf. Risério, 1981, p. 114; Góes, 1982, p. 76-77).

A partir de meados dos anos 1970, a criação musical seguiu um rumo

${ }^{9} \mathrm{O}$ abadá só foi criado em 1992, e sua criação é reivindicada pelo bloco de trio Eva. (cf. www.vol.com.br/ grupoeva/blocoeva/ mdlx [25 janeiro 1997]). totalmente diferente, influenciada então pela "reafricanização" do carnaval baiano. Caracterizada pelo revigoramento dos afoxés e o surgimento de blocos afros, essa reaparição do elemento negro-mestiço da população no primeiro plano do cenário carnavalesco foi marcada por sua dimensão de reivindicação identitária, expressa sobretudo na parte musical e estética. Em 1979-1980, como fruto da inventividade que proporciona a festa, operou-se outra fusão musical: a 
GAUDIN, Benoit. Da mi-carême ao carnabeach - história da(s) micareta(s). Tempo Social; Rev. Sociol. USP, S. Paulo, 12(1): 4768 , maio de 2000.

integração do ritmo dos afoxés, o ijexá, ao som dos trios (dando o chamado frevoxé) por artistas como Morais Moreira, com sua música Assim pintou Moçambique (cf. Risério, 1981, p. 115). Outros ritmos, oriundos principalmente do Caribe, como a salsa, o merengue, o reggae e a lambada (cf. Moura, 1987, p. 19), vieram depois se misturar ao "som dos trios" e essa constante renovação/ inovação foi desembocar num estilo que recebeu o nome de axé-music.

Esse fase de influência mais "tropical" na inovação musical dos trios caracteriza o início de uma nova era para o carnaval de Salvador, a da integração do elemento estético-rítmico de origem africana pelo trio elétrico. E essa nova etapa do carnaval aconteceu logo no mesmo momento em que surgiam os primeiros blocos de trio, operando assim verdadeira revolução, tanto musical como organizacional, do modelo festivo baiano.

Com o surgimento dos blocos de trio, que deram nova vida ao carnaval de trio, e a "reafricanização", sobretudo musical e estética dos festejos, criou-se um círculo virtuoso de dinamização do carnaval baiano: encontrando inspiração nos ritmos negros e financiamento nos blocos de trio, a criação e a produção musical passaram a prosperar bastante (cf. Loiola \& Miguez, 1996, p. 50-51). Dessa maneira, o modelo festivo baiano ganhou nova feição, mais original e diversificada, caraterizada por um estilo musical próprio e agremiações originais (afoxés, blocos afros, blocos de trio). O carnaval de Salvador entrou então numa fase de sucesso crescente, envolvido numa dinâmica sinergética dupla, formada de um lado por um pólo estético-musical de origem africana e do outro lado por um pólo econômico caracterizado pelo sistema de gerenciamento dos blocos de trio.

\section{Os blocos de trio ingressam no ramo da indústria cultural}

Ao integrar os trios elétricos, os blocos de trio ganharam atitude e estrutura empresariais. A tendência a superar o amadorismo da organização tradicional dos blocos começou logo em 1978, por iniciativa do Camaleão (cf. Miguez, 1996, p. 75) e foi rapidamente copiada pelos demais. A nova estrutura da agremiação (que, embora tome feições de verdadeira empresa comercial, continua isenta de impostos por permanecer juridicamente "sem fins lucrativos") é, via de regra, uma estrutura empresarial bastante enxuta, formada basicamente por diretores (para as funções como finanças, marketing, produção e gerenciamento das bandas e artistas) e uma dezena de funcionários fixos, cuidando de atividades administrativas e de rotina como recepção e atendimento, apoio e outros serviços gerais. No carnaval, porém, a empresa-bloco passa a empregar várias centenas de pessoas, recorrendo massivamente à terceirização, sobretudo para as atividades ligadas à segurança e ao atendimento dos foliões durante a festa ${ }^{10}$. Lançam mão também de alternativas originais em matéria de contratação, criando as figuras de "comissário", "delegado" e "agente" que são foliões encarregados da difusão e da venda do produto-bloco em troca da indumentária do bloco ou de reduções de preços nos shows ou atividades organizadas pelo bloco (cf. Miguez, 1996, p. 78).
${ }^{10}$ Foram os blocos de trio que, de maneira pioneira, introduziram no carnaval os carros de apoio (com bar, sanitários e primeiros socorros) para atender seus "associados" durante o desfile. E essas mordomias necessitam de uma mão-deobra numerosa. 
11 Sobre os blocos afro e sua evolução, cf. Morales (1990, 1991), Dantas (1993) e Jesus (1991).
Outra característica marcante, pelo menos para os blocos maiores que formam o chamado "primeiro grupo" (Internacionais, Camaleão, Cheiro de Amor, Eva, Pinel, Pike, entre outros), é de ter integrado as funções de produtoras artísticas, isto é, de se tornarem ativos em atividades como lançamento de cantores, produção de discos, organização de shows, etc. (cf. Miguez, 1996, p. 79). Essa diversificação das atividades dos blocos de trio se explica primeiro pelos contatos privilegiados que teceram com as bandas enquanto empregadores dos músicos durante o carnaval: os donos dos blocos tinham posição favorecida e interesse próprio para produzi-los. Afinal, o sucesso de um bloco depende sobremaneira da popularidade da sua banda. Muitos cantores e bandas, aliás, se beneficiaram dessas atividades dos blocos, ganhando espaço na mídia, discos no mercado e fama no país. Outro fator em favor da diversificação das atividades dos blocos de trio foi sua própria estrutura empresarial: como qualquer empresa, os blocos tinham necessidade de trabalhar não somente durante o carnaval mas também ao longo do ano e a produção musical e a promoção de eventos ofereciam essa possibilidade.

A partir da metade dos anos 80, o carnaval de Salvador já tinha desenvolvido e consolidado plenamente suas características de miscigenação da organização comercial com a "africanização" estético-musical: as bandas de blocos de trio começavam a tocar um ritmo nitidamente influenciado pela música de origem africana (o axé-music) e, por outro lado, os blocos afros começavam a ingressar na indústria de produção cultural. Como primeiros passos desse processo, Moura (1987, p. 19 e 26-28) cita a participação de blocos afros numa coletânea em 1982, um compacto de reggae em 1983 e o primeiro elepê do Ilê Aiyê em 1984, precedendo o hit Faraó de Olodum em 1986. Anos mais tarde, os principais blocos afros já haviam adotado estrutura organizacional parecida com a dos blocos de trio, com a diferença de manter parte de suas atividades voltada para sua comunidade de origem ${ }^{11}$.

Com os primeiros discos dos blocos afros e o sucesso nascente do axémusic, explodiu o mercado regional de música. A "música de carnaval” passou a ser ouvida durante todo o ano, os Dias Gordos se tornando sua apoteose (cf. Dias, 1996, p. 114). No rastro da bandas mais famosas, surgiram dezenas de bandas menores, favorecidas pelo desenvolvimento do mercado e da infra-estrutura de produção da crescente indústria cultural baiana (cf. Andrade, 1996, p. 56-58).

Outro salto quantitativo ocorreu no mundo da música e do carnaval baiano quando, na virada da década de 1990, houve uma onda nacional e internacional de interesse pela cultura baiana. O disco que o cantor norte-americano Paul Simon gravou com o Olodum e o tombamento pela Unesco do bairro do Pelourinho como patrimônio da humanidade foram os primeiros acontecimentos que atraíram a atenção mundial sobre Salvador e, por extensão, sobre toda a Bahia. Esse movimento fundamentado na então nascente World Music e no interesse pelas particularidades turísticas do Brasil virou moda nos Estados Unidos e na Europa, e por tabela, no próprio Brasil. O ritmo musical do carnaval de Salvador recebeu então enfoque especial da mídia e, atrás do sucesso nacional e internacional dos precursores (Olodum e Daniela Mercury), as bandas locais de axé-music começaram a fazer sucesso fora do seu estado e do país. 
GAUDIN, Benoit. Da mi-carême ao carnabeach - história da(s) micareta(s). Tempo Social; Rev. Sociol. USP, S. Paulo, 12(1): 4768 , maio de 2000.

\section{O sucesso turístico da Bahia e a racionalização da organização do seu carnaval}

Este sucesso das manifestações culturais baianas (carnaval e música), a liado a um contexto econômico-turístico favorável a nível nacional (declínio do poder atrativo do Rio de Janeiro no mesmo momento em que se consolidava a indústria nacional de turismo e lazer), criou condições para uma verdadeira "redescoberta" do Nordeste pelos turistas nacionais e internacionais, redescoberta que beneficiou principalmente o estado da Bahia (Porto Seguro e Salvador).

O governo desse estado nordestino, aliás, desempenhou papel pioneiro na divulgação das atrações turísticas da sua terra, recorrendo, já nos anos 80, ao patrocínio de bandas de axé como Chiclete com Banana para promover no país inteiro suas belezas naturais e atrações culturais (cf. Veja, 1996b, p. 112). Essas ações de patrocínio político das bandas (que continuam ainda hoje) faziam parte da estratégia de uma ambiciosa campanha de marketing fundamentada na criação de uma nova imagem da Bahia. Segundo essa campanha, que se sistematizou a partir de 1991 (cf. O Povo, 1997b), o "produto-Bahia" a ser comercializado tinha uma imagem de paraíso tropical, de terra de sol e de festas, de muitas praias e de povo jovem, bonito e alegre, imagem que se contrapunha radicalmente ao estereótipo tradicional do Nordeste, terra de seca e de gente sofrida, de retirantes e de velhas oligarquias. Essa nova imagem da Bahia e, por extensão, do Nordeste, foi divulgada e amplificada pela mídia nacional (cf. Mamede, 1996) através de reportagens, propagandas e até telenovelas. Levas inteiras de turistas paulistas, cariocas, sulistas e até argentinos foram assim seduzidos e passaram a ir desfrutar suas férias e o carnaval em Salvador.

A partir de 1990-1991, o número de turistas que afluem para Salvador durante o Carnaval não pára de crescer, aumentando o volume de negócios na cidade: os hotéis ficam lotados, as bandas vendem mais discos, os blocos mais abadás, e as agências de viagem trabalham agora em parceria com eles, incluindo os abadás nos seus pacotes (cf. Dias, 1996, p. 114), oferecendo assim a mais perfeita expressão do produto "Bahia-festa". Para responder à decorrente expansão do mercado, os blocos de trios criaram "blocos alternativos" no trecho nobre da orla (Barra-Ondina), trecho que se tornaria o novo e badalado circuito do carnaval na década de 1990.

Já existiam blocos "alternativos" desde o final dos anos 80, "quando algumas novas agremiações carnavalescas, ao adotarem a sexta-feira e o sábado para saírem às ruas, assumem-se como alternativa de diversão aos dias do tradicional desfile de blocos na Avenida, de domingo a terça-feira" (Miguez, 1996, p. 81). Na época, porém, esses "alternativos" não eram blocos de trio mas sim simples blocos e cordões que se reuniam perto do farol da Barra. Sob a pressão dos grandes blocos de trio da cidade que usavam seus recursos (trios, contatos com as bandas, etc.) para expandir suas atividades lançando seus "alternativos", a reunião pré-carnavalesca da Barra se transformou rapidamente num desfile que, seguindo a orla, chegou até o bairro de Ondina, abrindo assim um novo circuito, também chamado de "alternativo" (cf. Miguez, 1996, p. 81) 
Até 1993, o carnaval cresceu de forma muito caótica pois os blocos de trio não paravam de criar blocos alternativos e "alternativos de alternativos". Dessa forma, a festa passou rapidamente a transbordar seus limites tradicionais, o circuito Centro Histórico-Campo Grande, tornando-se, a cada ano, mais congestionado, impossível de organizar e inadequadamente dotado em serviços e infraestrutura (cf. Costa, 1996, p. 5). Em 1993, o circuito Barra-Ondina ganhou reconhecimento oficial, e a prefeitura municipal de Salvador começou a encarar o carnaval como um produto mercadológico: inspirando-se em técnicas de gerenciamento de cunho empresarial, regulamentou o que era pouco ou mal organizado, abriu licitações públicas em áreas onde antes reinava o clientelismo político e reuniu todas as entidades, agremiações e empresas envolvidas no evento em congressos e no seio do seu Conselho do Carnaval para tomar as decisões de forma colegiada. Ampliou e modernizou também o policiamento e os serviços de atendimento médico: em suma, racionalizou, profissionalizou e comercializou a organização do evento (cf. Costa, 1996, p. 7-9).

\section{Os artistas tornam-se empresários}

Muitos artistas e bandas de axé, que gozam hoje de sucesso nacional, começaram como simples “puxadores de bloco" no final dos anos 1970, a exemplo do Chiclete com Banana que existia há anos, com outro nome e pouco sucesso. Contratados por blocos de trio, foram descobertos, lançados e produzidos pelas produtoras musicais ligadas a esses blocos.

Nessa história de sucesso das bandas baianas, vale ressaltar o papel decisivo do apoio político do Governo do Estado da Bahia: ao contrário de outros governos estaduais, a Secretaria Estadual da Cultura daquele estado investiu desde os anos 80 na música popular comercial da sua terra. Bandas e artistas como DanielaMercury, Netinho, Olodum, Chiclete comBanana, Ara Ketu, Asa de Águia, Ilê Aiyê receberam, em alguma ocasião, o apoio financeiro dos sucessivos governos estaduais baianos, para os fins mais diversos, que iam da simples animação de comícios eleitorais a campanhas nacionais e internacionais de divulgação do carnaval de Salvador. Da mesma forma, e ainda com o objetivo de atrair turistas para o Estado, esses subsídios públicos desempenharam papel decisivo no lançamento nacional do axé-music (cf. Veja, 1996b, p. 112).

Ao fazer sucesso, as bandas de axé tornaram-se indispensáveis aos blocos, constituindo um elemento importante no processo de manutenção da fidelidade dos seus associados. Logicamente, passaram a cobrar cachês cada vez mais caros, e acabaram, às vezes, tornando-se co-proprietários dos blocos, como por exemplo o Chiclete com Banana que adquiriu parte do bloco Camaleão (cf. Miguez, 1996, p. 79-80). Outros, como a Banda Eva ou a banda Cheiro de Amor, para citar as mais famosas, partiram para outra solução empresarial: a criação e a direção dos seus próprios blocos, no caso, os blocos Eva e Cheiro de Amor.

Embora, em geral, permaneçam contratados como atrações principais ou exclusivas dos grandes blocos de trio, vários desses artistas e bandas dispõem hoje de trios elétricos próprios que lhes permitem participar das 
GAUDIN, Benoit. Da mi-carême ao carnabeach - história da(s) micareta(s). Tempo Social; Rev. Sociol. USP, S. Paulo, 12(1): 4768 , maio de 2000.

micaretas com maior confiabilidade na parte técnica (em vez de se apresentar num trio alugado, de qualidade desconhecida) e maior lucro (cobrando dos blocos das micaretas o aluguel do trio, além do seu próprio cachê).

Outra opção de atividade empresarial para os músicos foi a criação de blocos alternativos como o Cocobambu, pertencente a Durval Lelis (Asa de Águia), do Jheremias, propriedade de Netinho, do Nana Banana e Nana Pipoca, pertencente ao Chiclete com Banana em parceria com o Camaleão, ou do A Barca, cujo dono é a banda Cheiro de Amor (cf. Miguez, 1996, p. 79). Esses blocos alternativos, como os "oficiais" aliás, se desdobram geralmente em franquias nas principais micaretas do país, multiplicando as atividades e o lucro de seus donos. Os blocos que pertencem a Durval Lelis, por exemplo, contabilizavam, já em 1996, 17 franquias espalhadas pelo país (cf. Veja, 1996a, p. 107).

Na parte da produção musical em si, vários artistas deixaram de trabalhar como meros prestadores de serviços, abrindo, já no final dos anos 80, suas próprias produtoras, como a Canto da Cidade de Daniela Mercury, Duma de Durval Lelis, Mazana da banda Chiclete com Banana ou a M.E. do cantor Netinho. Alguns anos mais tarde, com a explosão do carnaval de Salvador e o conseqüente aumento das suas atividades (blocos alternativos, micaretas, shows...), alguns artistas - como Netinho, por exemplo - alcançaram um nível superior na cadeia da produção musical: montaram seus próprios estúdios de gravação, selos e editoras musicais, conseguindo um maior controle sobre a produção e a distribuição dos discos (cf. Miguez, 1996, p. 79; Veja, 1996a, p. 107).

Do ponto de vista artístico-musical, essa evolução da música de carnaval, ao mesmo tempo que "pasteurizava" e comercializava um certo tipo de ritmo, criou terreno fértil para o surgimento permanente de novas bandas, novas músicas, novas danças... A produção musical da Bahia, além de se intensificar, ganhou espaço privilegiado na mídia nacional: cada lançamento ou "descoberta" no mercado baiano passou a invadir as ondas do país inteiro, impondo-se ao gosto musical das massas. Nesse quadro, o carnaval é agora considerado como uma mera vitrine que permite divulgar um nome ou um disco para conseguir resultados comerciais como programas de televisão, vendagem de discos ou convites para animar micaretas...

\section{As micaretas fora da Bahia}

O sucesso turístico da Bahia, e mais especificamente seu carro-chefe, o carnaval de trio, despertou nos outros estados da região Nordeste o interesse tanto das autoridades públicas como da iniciativa privada: os primeiros queriam entrar "na onda baiana" e atrair turistas para seus estados, enquanto os empresários se interessavam mais pela nova forma de negócio que representava a organização de festas na base do bloco-empresa. Por isso, entre 1990 e 1993, com poucos meses de intervalo entre si, surgiram iniciativas para copiar o modelo festivo de Salvador, importando o que ele tinha de mais atraente e comercial: o desfile dos trios elétricos animados pelas badaladas bandas de axé. Foi assim, como fruto de iniciativas ora públicas ora privadas, 
que foram idealizadas e lançadas as primeiras micaretas fora da Bahia.

A estreante Micarande nasceu de um projeto montado pelo Departamento Municipal de Turismo da prefeitura de Campina Grande, na Paraíba, em abril de 1990 (cf. www.micarande.com.br [13 setembro 1997]). Já em Natal, no Rio Grande do Norte, a prefeitura municipal lançou, no final de 1991, uma campanha chamada "Natal em Natal" para atrair turistas ao seu estado. Para multiplicar os atrativos da sua cidade, encarregou uma empresa privada, a Destaques Promoções, de organizar o "primeiro carnaval fora de época entre as capitais brasileiras", o Carnatal (cf. www.truenetrn.com.br/ carnatal [21 janeiro 1997]). Essa estréia era, antes de mais nada, a da primeira micareta organizada por uma empresa privada.

No caso de Fortaleza, foi um jovem empresário chamado Ailton Júnior que, por ter passado vários carnavais em Salvador e ficar entusiasmado tanto pela folia baiana quanto pelas perspectivas de negócios que ela proporcionava, idealizou em fevereiro de 1992 uma festa que alguns meses mais tarde (em julho) ia se transformar no Fortal (cf. Revista do Fortal, 1997, p. 46); nessa primeira edição, que na época integrava um conjunto de eventos pré-carnavalescos, a festa ainda não tinha nome. Também dificilmente pode ser considerada uma micareta pois punha em cena um único bloco, o Araboneco, puxado pela banda Cheiro de Amor. Apesar do amadorismo da organização, essa festa angariou certo sucesso (cf. O Povo, 1993).

Em julho e agosto de 1992, outros dois "embriões de micareta" surgiram também em Aracaju e Brasília como fruto de iniciativas de jovens empresários locais. Em Aracaju, a festa se chamava Suas férias com amor e era animada por três blocos; no ano seguinte (1993) se repetiu com maior estruturação e ganhou outro nome: Pré-Caju (www.200.241.50.35/precaju/ hist [14 setembro 1997]). Em Brasília, a Micarecandanga já nasceu com seu nome definitivo, mas atravessou momentos críticos nos seus dois primeiros anos (cf. Hollanda, 1996, p. 83).

Interessante é notar que, no caso do primeiro Pré-Caju (em 1993), a festa não aconteceu em julho, como no ano anterior, mas sim em fevereiro, pois àquela altura, o Fortal já tinha sido criado pela empresa Click Promoções e sua data estrategicamente transferida para o último final de semana de julho, época de fim de férias e de alta estação turística de inverno. As datas das férias letivas e dos feriados nacionais passaram a partir daí a ser duramente disputadas pelas maiores micaretas, todas querendo firmar contrato com as maiores bandas baianas programando-as em datas turisticamente interessantes.

Em seguida veio o Recifolia, organizado pela prefeitura de Recife em outubro de 1993, que seria acompanhado aos poucos por quase todas as capitais do país... Todas essas festas se inspiravam no modelo carnavalesco baiano (o desfile de trio) e nos modelos organizacionais dessas micaretas pioneiras da região Nordeste: micaretas de prefeituras (como a Micarande ou o Recifolia) ou micaretas de empresas privadas, as chamadas "promotoras de evento" (como o Carnatal, o Fortal, o Pré-Caju ou a Micarecandanga).

Ao ser "exportada" da Bahia, a micareta sofreu portanto diversas 
GAUDIN, Benoit. Da mi-carême ao carnabeach - história da(s) micareta(s). Tempo Social; Rev. Sociol. USP, S. Paulo, 12(1): 4768 , maio de 2000.

transformações: seus festejos ficaram menos diversificados do que em Feira de Santana e nas outras cidades baianas onde as micaretas são verdadeiros "carnavais fora de época", com todas as atividades festivas dos Dias Gordos: entrega das chaves da cidade a um rei Momo que reina durante os festejos, bailes nos clubes sociais da cidade, desfile de blocos, de cordões, de afoxés e de qualquer outro tipo de agremiação... Já nas cidades e capitais que sediam micaretas fora da Bahia, os festejos se restringem, via de regra, a um simples desfile de trios elétricos, repetido a cada dia que dura a festa ${ }^{12}$.

Outra transformação de porte é o avanço da iniciativa privada na organização da festa: nas cidades cuja prefeitura deixou (por uma razão qualquer) de montar sua micareta, surgiram empresas para idealizar a festa e cuidar da sua organização. Vale aqui destacar o papel determinante desenvolvido pelas empresas privadas, caracterizando uma nítida evolução do tipo de grupo social que organiza e produz eventos festivos.

O sucesso das primeiras micaretas fora da Bahia (de 1990 até 1993) foi rápido e unânime, superando todas as expectativas dos organizadores: todos os blocos de trio vendiam seus abadás meses antes da festa, quaisquer que fossem seus preços ${ }^{13}$. Os turistas afluíam, o volume de negócios aumentava e o sucesso não era somente comercial, como também de público: centenas de milhares de foliões não pagantes, os chamados "pipocas", juntavam-se ao longo das avenidas dos desfiles para ver as "bandas baianas" passarem. A tal ponto que, em várias cidades, como Fortaleza por exemplo, a micareta tornou-se o maior evento cultural do ano, sobrepujando o próprio carnaval, as festas juninas ou qualquer outra festa...

A partir de 1993, as micaretas se multiplicam de maneira desenfreada: com o sucesso das micaretas nas capitais do Nordeste e a explosão do carnaval de Salvador, o modelo festivo baiano foi (e continua sendo) copiado por inúmeras cidades do Nordeste e do país inteiro. Essa última onda de propagação da festa está acontecendo em dois eixos principais: primeiro, em direção às cidades interioranas e, por outro lado, para as capitais e metrópoles do país que ainda não haviam sido atingidas pela folia "fora de época".

Em 1994, já eram 23 micaretas e, em 1995, seu número passou para 29 (cf. Bernardes, 1995, p. 78). Depois dessa data, fica praticamente impossível registrar o número de novas festas micaretescas que nasceram no país. A título de exemplo, somente no estado do Piauí havia em 1997 nada menos do que 6 micaretas (nem todas, é claro, animadas pelas mais famosas bandas baianas). Lugares que nunca antes tiveram carnaval (a exemplo de várias cidadezinhas sertanejas), bem como metrópoles cultivando tradicionais atividades momescas (como Rio de Janeiro ou São Paulo) organizam agora suas micaretas. O modelo festivo baiano está tomando conta do país inteiro, se propagando ultimamente até no exterior, com no caso do carnabeach, que aconteceu pela primeira vez em Miami, em 1997, organizado pelo bloco cearense Sirigüela em parceria com a promotora de evento paraense "Bis Promoções" (cf. O Povo, 1997a).

De fato, essa segunda onda de propagação da micareta fora da Bahia apresenta a originalidade de não se irradiar somente a partir de Salvador, mas
${ }^{12} \mathrm{Na}$ Bahia, jornais e revistas designam às vezes as micaretas dos outros estados de carnavais temporãos reservando a terminologia de micareta para as festas de trio do interior baiano. Contudo, o tipo de festejos dessas duas categorias de eventos incitam mais a falar de carnaval temporão no caso das micaretas baianas...

${ }^{13} \mathrm{O}$ preço dos abadás é geralmente bastante salgado, podendo chegar à casa dos R\$ 400,00. 
também de outros centros urbanos, como Fortaleza ou Natal, que se tornaram grandes centros "micaretescos" e exportam seu know-how tanto para o interior do seus estados como para outras cidades do país ou do exterior (no caso do carnabeach). Essa tendência fica particularmente explícita no depoimento de Francisco Recarey Jr, idealizador do RioElétrico: "Eu fui no Fortal, em Fortaleza, e em cada esquina encontrava um carioca. Confirmei na prática o prestígio da axé-music e parti para a aventura" (Hollanda, 1996, p. 83).

\section{Tipificando...}

Tentando estabelecer uma tipologia das micaretas que existem hoje no país, podemos dividi-las entre as baianas, bastante diversificadas, e as demais, geralmente restritas a um mero desfile de trios. Outra divisão pode segregar as micaretas onde a prefeitura municipal contrata diretamente trios "independentes" (como nas pequenas cidades do interior da Bahia), outras em que a prefeitura é a própria promotora de um evento realizado por blocos de trio (como em Campina Grande ou Recife), e enfim micaretas em que a prefeitura não passa de um mero parceiro da empresa privada que organiza tudo (como, por exemplo, em Fortaleza ou Natal). Via de regra, porém, fica bastante difícil desvendar exatamente o papel e o grau de envolvimento das prefeituras municipais na organização dos festejos.

Entre os blocos, podemos distinguir as agremiações locais, oriundas e dirigidas por empresários da sua cidade, e as franquias e as joint-ventures de blocos baianos, que podem eventualmente pertencer a músicos ou bandas. Outra divisão existe também entre os blocos “oficiais" e os "alternativos", essa divisão decorrendo dos dias de saída do bloco. Por exemplo em Fortaleza, o Fortal "oficial" dura três dias (sexta-feira, sábado e domingo) e os blocos que desfilam nos dias anteriores (quarta-feira e quinta-feira) são chamados de "alternativos". Muitos deles são franquias de blocos baianos e pertencem a músicos ou bandas.

Do ponto de vista financeiro, os donos de blocos, baianos ou de outras cidades, lucram bastante com a organização da festa, bem como as empresas organizadoras, essas últimas sendo geralmente o alvo preferido de todas as críticas dos opositores a esse tipo de evento (referentes sobretudo ao pagamento de impostos e à utilização de locais públicos por empresas privadas). Mas quem lucra mais com a multiplicação das micaretas pelo país são sem dúvida os artistas-empresários "do primeiro grupo", aqueles que participam de até vinte micaretas por ano, muitas vezes em cima dos seus próprios trios (cf. Veja, 1996a, p. 106). Para citar novamente um exemplo do Fortal, a banda Chiclete com Banana anima o desfile do bloco "oficial" Sirigüela, empresa inteiramente cearense, durante a sexta-feira, o sábado e o domingo do Fortal. Nos outros dias (quarta-feira e quinta-feira), a banda se apresenta no bloco "alternativo" Nana Banana, franquia cearense do bloco baiano de mesmo nome que pertence à própria banda. Os músicos-empresários aproveitam assim o trio que trouxeram de Salvador (também propriedade deles) para se apresentar nos dois blocos, um vez como contratados, outra vez por conta própria... No final das contas, por- 
GAUDIN, Benoit. Da mi-carême ao carnabeach - história da(s) micareta(s). Tempo Social; Rev. Sociol. USP, S. Paulo, 12(1): 4768 , maio de 2000.

tanto, entre as franquias de blocos, os cachês dos músicos e os outros serviços prestados, grande parte do dinheiro arrecadado pelas micaretas volta, de uma forma ou outra, para a Bahia (cf. Gaudenzi, 1996, p. 13).

Tentando sintetizar a história da expansão da micareta, nota-se que a festa se propagou por ondas sucessivas, a partir da cidade de Salvador e acompanhando a evolução do seu carnaval. Assim, o surgimento no Recôncavo das primeiras mi-carêmes de tipo "segundo carnaval do ano" respondia à volta do sucesso do carnaval na capital e ao decorrente enfraquecimento dos carnavais do interior próximo. Uma segunda onda de propagação, para além do Recôncavo, aconteceu quando apareceu o trio elétrico em Salvador: foi a época dourada do trio para todos, sem cordas. O terceiro movimento, que deu novo fôlego à festa e proporcionou-lhe a oportunidade de se espraiar pela Bahia inteira, foi a integração dos trios pelos blocos e o sistema de financiamento que dela decorreu. Quarta onda de propagação da festa aconteceu com o sucesso do axé-music e o deslanche do turismo na Bahia, fatos que incitaram a maioria das capitais nordestinas a adotarem a micareta. A última onda de propagação, que continua ainda hoje e atinge um número considerável de cidades interioranas e de capitais, parece sustentar-se tanto da demanda de opções de lazer por parte da população, como do efeito de moda que caracteriza a "música baiana" e a festa de trio. Mas a análise do sucesso popular e nacional de uma festa tão baiana e tão comercial constitui um tema de pesquisa em si, que não cabe neste artigo...

Recebido para publicação em agosto/1998

GAUDIN, Benoit. From mi-carême to carnabeach - the history of the micareta(s). Tempo Social; Rev. Sociol. USP, S. Paulo, 12(1): 47-68, May 2000.

ABSTRACT: The purpose of this paper is to provide insights into the history of the micareta in Brazil, from its origin as a mi-carême (mid-lent celebration) to its current expression. Although this research is in part a synthesis of the rare publications on the subject, most of the data comes from extensive historical archive research, carried out mainly in the Brazilian national and local press. The micareta is an old festival (started in 1908) and its history is closely linked to the carnival in Salvador. It resulted from an evolution of the trio elétrico and from the Bahian trio bands. Tied in with the successive waves of expansion of the micareta throughout Brazil, five distinct developmental stages are discussed. Their salient features reflect the gradual commercialization of the micareta.
UNITERIMS:

Carnival, marketing of culture, cultural industry, cultural history, mi-carême, micareta, trio elétrico. 


\section{REFERÊNCIASBIBLIOGRÁFICAS}

AlenCAR, Helder. (1968) 31 anos de micareta. Feira de Santana, mimeo.

Andrade, Carla Guimarães de. (1996) O axé music abre caminho para o som underground. Bahia Análise e Dados, Salvador, 5(4): 56-58, Carnaval, março.

A Tarde. (1977a) Dois blocos com trios elétricos. Salvador, 01/02, p. 10. . (1977b) Traz Os Montes 77. Salvador, 08/02.

(1978) Comercialização estaria descaracterizando os trios. Salvador, 01/02.

. (1997) Micareta na terra do frio em abril. Salvador, Caderno de turismo, 26/03, p. 3.

BASTIDE, Roger. (1970) Le proche et le lointain. Paris, Ed. Cujas.

BAROJA, Julio Caro. (1979) Le carnaval. Paris, Gallimard.

Bernardes, Ernesto. (1995) Festejar é preciso. Veja, São Paulo, 28(26): 7879, 28 de junho.

Costa, Luiz Afonso. (1996) Um salto planejado. Bahia Análise e Dados, Salvador, 5(4): 5-11, Carnaval, março.

Dantas, Marcelo. (1993) Olodum: de bloco afro a “holding” cultural. Salvador, 130p. Dissertação (Mestrado). Faculdade de Administração da Universidade Federal da Bahia.

DiAs, Climaco. (1996) Carnaval prêt-à-porter. Bahia Análise e Dados, Salvador, 5(4): 113-115, Carnaval, março.

Diego, Pilar García de. (1960) Censura popular. Revista de Dialectología y Tradiciones Populares, XVI.

Duarte, José Carlos. (1997) A trajetória da micareta. A Tarde, Salvador, 08/ 02, Caderno Cultura, p. 4.

Feira Hoje. (1987) Um pouco de história. Feira de Santana, 01/05, p. 5-6.

Folha do Norte. (1928) O segundo carnaval do anno em Irará. Feira de Santana, $31 / 03$.

Gaudenzi, Paulo. (1996) Turismo e carnaval: uma estratégia de ação do Estado da Bahia. Bahia Análise e Dados, Salvador, 5(4): 13-18, Carnaval, março.

Godi, Antônio Jorge Victor dos Santos. (1991) De índio a negro, ou o reverso. Caderno CRH. Suplemento Cantos e Toques, Salvador, p. 51-71.

GóEs, Fred de. (1982) O país do carnaval elétrico. Salvador, Corrupio.

GoMEs, Olívia Maria dos Santos. (1989) Impressões da festa: blocos afro sob olhar da imprensa baiana. Estudos Afro-Asiáticos, Salvador, p. 171-185. 
GAUDIN, Benoit. Da mi-carême ao carnabeach - história da(s) micareta(s). Tempo Social; Rev. Sociol. USP, S. Paulo, 12(1): 4768 , maio de 2000.

FAURe, Alain. (1978) Paris, carême prenant: du carnaval à Paris au XIXe siècle (1880-1914). Paris, Librairie Hachette.

Fry, Peter, CARrara, Sérgio \& Martins-Costa, Ana Luiza. (1988) Brancos e Negros no Carnaval da Velha República. In: ReIs, João José (org.). Escravidão e invenção da liberdade. São Paulo, Brasiliense, p. 232-263.

Hollanda, Eduardo. (1996) Carnaval a toda hora. Isto É, São Paulo, (1410): 82-83, 09 de outubro.

Jesus, Ericvaldo Veiga de. (1991) Bloco afro Muzenza: “clareza da vida” e “Vôo da imaginação”. Salvador, 232 p. Dissertação (Mestrado). Faculdade de Ciências Sociais da Universidade Federal da Bahia.

Loiola, Elizabete \& Miguez, Paulo. (1996) Lúdicos mistérios da economia do carnaval baiano: trama de redes e inovações. Bahia Análise e Dados, Salvador, 5(4): 45-55, Carnaval, março.

Mamede, Maria Amélia Bernardes. (1996) A construção do Nordeste pela mídia. Fortaleza, Secult.

Miguez, Paulo. (1996) Yes, nós temos Chiclete com Banana. Bahia Análise e Dados, Salvador, 5(4): 75-84, Carnaval, março.

Moraes, Eneida de. (1987) História do carnaval carioc. Rio de Janeiro, Record.

Morales, Anamaria. (1990) Etnicidade e mobilização cultural negra em Salvador. Salvador, 180 p. Dissertação (Mestrado). Faculdade de Ciências Sociais da Universidade Federal da Bahia.

.(1991) Blocos negros em Salvador: reelaboração cultural e símbolos de baianidade. Caderno CRH. Suplemento Cantos e Toques, Salvador, p. 72-93.

Moura, Milton. (1987) Faraó, um poder musical. Cadernos do CEAS, 112: 1029.

Nobre, Maria Tereza Roxo. (1978) Meandros de participação: formas de compartilhar o espaço. Ciência e Cultura, São Paulo, 30(5): 535-542, maio.

O Povo. (1993) Carnaval em julho: II Fortal reúne bandas baianas em Fortaleza. Fortaleza, 06/04.

. (1997a) Carnaval brasileiro invade Miami em julho. Fortaleza, 18/ 05, Caderno 3, p. 1.

(1997b) Bahiatursa trabalha com planejamento desde 1991. Fortaleza, 07/06.

Panorama da Bahia. (1985a) Em Feira, o carnaval de abril. Salvador, 20/02, p. 24.

. (1985b) Os donos da festa. Salvador, 05/04, p. 11-14.

. (1985c) Samba, chuva e suor. Salvador, 20/05, p. 38-39. 
. (1987) Uma festa de 50 anos. Salvador, 20/04, p. 12-17.

. (1988a) Micareta com muito brilho. Salvador, 28/04, p. $22-23$.

. (1988b) A volta da folia. Salvador, 21/05, p. 40-41.

Pedra Branca, Itaracy. (1985) Micareta boa e barata. Panorama da Bahia, Salvador, 05/04, p. 4.

PopPIno, Rollie E. (1968) Feira de Santana. Salvador, Itapuã.

QueIroz, Maria Isaura Pereira de. (1992) Carnaval brasileiro: o vivido e o mito. São Paulo. Brasiliense.

Revista do Fortal. (1997) Célio e Júnior: uma parceria que deu certo. Fortaleza, 1(1): 46-47, julho.

RiséRIO, Antônio. (1981) Carnaval Ijexá. Salvador, Corrupio.

SAmpaIo, Maria Inês. (1983) Le chat mis à mort. Tragédie de la joie ou le Carnaval de Bahia. Nouvelle Revue d'Ethnopsychiatrie, 1: 81-107.

SEbe, José Carlos. (1986) Carnaval, carnavais. São Paulo, Ática.

Veja. (1982) O carnaval elétrico. São Paulo, 24/02, (703): 38-44. . (1996a) Farra milionária. São Paulo, 17/01, 27(1427): 106-107. . (1996b) Batucada oficial. São Paulo, 04/09, 29(1460): 112-113.

Verger, Pierre. (1980) Procissões e carnaval no Brasil. Ensaios e Pesquisa, Centro de Estudos Afro-Orientais, UFBA, Salvador, (5): 1-15, outubro.

VianNA, Hildegardes. (1965) Do entrudo ao carnaval na Bahia. Revista Brasileira de Folclore, Rio de Janeiro, (13): 283-298.

. (1970) Micareta, carnaval temporão. Aratu, Salvador, 3(32): 24, abril.

VIEIRA FILHo, Raphael Rodrigues. (1995) A africanização do carnaval de Salvador, BA - A re-criação do espaço carnavalesco (1876-1930). São Paulo, 220 p. Dissertação (Mestrado). Faculdade de História da Pontifícia Universidade Católica.

Von Simson, Olga Rodrigues de Moraes. (1984) A burguesia se diverte no reinado de momo. São Paulo, 283 p. Dissertação (Mestrado). Faculdade de Filosofia, Letras e Ciências Humanas da Universidade de São Paulo.

(1985) Os poderes públicos e a imprensa na transformação do carnaval paulistano do século XIX. Cadernos CERU, São Paulo, (1): 65-78, $2^{\text {a }}$ série. 